\title{
EFFECT OF SN ADDITION ON MECHANICAL PROPERTIES AND CORROSION RESISTANCE OF Al-Cu IN THE PRESENCE OF $\mathrm{H}_{2} \mathrm{O}_{2}$
}

\author{
Sabah Mahdi Salah ${ }^{1}$, Mohammed S. Ahmed ${ }^{1}$ \\ ${ }^{1}$ College of Engineering, Mechanical Engineering Department, Tikrit University, Iraq \\ E-mails:Sabahmsalih69@gmail.com, Mohammed.sa1972@gmail.com
}

\begin{abstract}
Corrosion of $\mathrm{AlCu}-\mathrm{xSn}$ alloys was investigated at $0,0.1,0.2$ and $0.5 \% \mathrm{H} 2 \mathrm{O} 2$ concentration in deionized water at neutral $\mathrm{pH}$. The aim of this work was to study the effect of $\mathrm{Sn}$ concentration in alloy on its dynamic corrosion in the presence of $\mathrm{H}_{2} \mathrm{O}_{2}$ oxidizer. The concentration of $\mathrm{Sn}$ in the alloy was $0 \%, 1 \%, 2 \%$ and $3 \%$. Potentiodynamic polarization of the alloys in different concentration of $\mathrm{H}_{2} \mathrm{O}_{2}$ was obtained to understand their electrochemical behavior. The dynamic corrosion tests were conducted by immersing the samples in beakers on a magnetic stirrer. The corrosion rates were calculated via weight loss measurements. The corrosion rates obtained show an increase with $1 \% \mathrm{Sn}$ in the alloy as compared to Sn free AlCu. However, beyond $1 \%$ till $3 \%$ an almost linear decrease in corrosion rates have been observed. The samples had the surface roughness before corrosion tests however after the tests the roughness values show the same trend as corrosion behavior which can be attributed to their wettability behavior.
\end{abstract}

Keywords: Corrosion, AlCu-xSn Alloys, Potentiodynamic Polarization, Surface Roughness, Mechanical Properties.

\section{Introduction}

Aluminium and its alloys offer a wide range of mechanical and electrical properties that upond precise engineering can meet the demands of both general and specific applications. Owing to its various industrial applications, aluminium and its alloys and their nontoxic nature, good weld-ability, ability to retain strength at lower temperatures and high strength to weight ratio have attracted the attention of many researchers [1-3]. Another important property of Aluminium alloys is their resistance to degradation and corrosion [4-6]. This property is due to the formation of a natural protective oxide layer of around $5 \mathrm{~nm}$ on its surface which offers good corrosion resistance towards natural atmospheres and other environments [7]. Although, due to corrosive attack of aggressive ions like chloride this protective layer can be locally destroyed which with time propagates and can result in failure [8]. However, if appropriately protected, aluminium alloys may have longer service life and be more reliable.

Corrosion by pitting in aluminium alloys can be affected by several factors such as the temperature, the $\mathrm{pH}$ and the type of ion present in the environment [9-12]. Another factor is that the electrochemical nature of the intermetallic phases can also results in localized corrosion in alloys. Several researchers have investigated the corrosion behaviour of aluminium alloys as a function of concentration of active element addition [4, 12-15], time and surface roughness [16], concentration of salt i.e. $\mathrm{NaCl}[4,16]$, acidic/basic nature of environment [4,7,14-17]. However, these investigations have been conducted in static conditions and acidic or basic environments in the absence of an oxidizer. Aluminum is generally anodic in nature [4] in mostly used media as compared to other metals in its alloys and therefore tend to suffer from localized type of corrosion may lead to formation of different cathodic precipitates. Although it is well understood that some inhibitors can protect aluminum and its oxide film from corrosion attacks.

In the present work, the main objective of is to observed the effect of Sn addition on the corrosion behaviour of $\mathrm{AlCu}-\mathrm{xSn}$ alloy in the presence of varying $\mathrm{H}_{2} \mathrm{O}_{2}$ concentration in DIW under dynamic conditions. The work provides a relation between the wettability, electrochemical behaviour of the alloy and dynamic corrosion rates. The work also relates the corrosion rates to surface roughness of alloy before and after dynamic corrosion.

\section{Materials and Methods}

\subsection{Materials}

A proper appearance of the paper will help the reader go through it more easily. To obtain it, is imperative that authors use this template. 
The aluminum alloy (Al-Cu-xSn) with chemical composition (weight \%) is listed in Table 1 has been investigated for its corrosion behavior. The alloys were prepared by adding pure tin (99.92\%) to pure aluminum (99.96) in the presence and absence of pure copper $(99.96 \%)$ through the casting process in a metal mold intended for this purpose.

Table 1. Chemical composition of the AlCu-xSn alloy

\begin{tabular}{|c|c|c|c|}
\hline Element & Al & $\mathbf{C u}$ & Sn \\
\hline $\mathbf{\%}$ & Balance & 4 & 0 \\
\hline $\mathbf{\%}$ & Balance & 4 & 1 \\
\hline $\mathbf{\%}$ & Balance & 4 & 2 \\
\hline$\%$ & Balance & 4 & 3 \\
\hline
\end{tabular}

\subsection{Methods}

\subsubsection{Sample Preparation}

The samples were prepared by cutting the alloy into $10 * 10 * 2 \mathrm{~mm}$ coupons and then mechanically polished using 1200 silicon carbide papers while lubricated with tap water. The prepared samples were cleaned with ethanol, washed with distilled water, dried with pressurized air and stored in desiccators prior to use.

\subsubsection{Hardness Measurement}

The hardness of aluminum copper alloys with tin addition after mechanical polishing treatments were evaluated using Vickers hardness test protocol with ARS9000 Full Automatic Micro hardness testing system (Future Teach, FM-300e, Kanagawa, Japan) with applied load of 500g. Three values were taken on each sample to calculate the average hardness value.

\subsubsection{Contact angle measurement}

The samples were characterized for wettability after CMP treatments through contact angle measurements with DIW. The contact angles were measured via sessile drop method using KSV ATTENSION Theta Lite Optical Goniometer.

The size of the drop was maintained at $\sim 150 \mu \mathrm{m}$.

Three tests were performed for each sample at room temperature and the results were averaged.

\subsubsection{Potentiodynamic polarization}

Potentiodynamic polarization technique was utilized in order to understand the electrochemical behavior of the alloys' corrosion.

All tests were performed with Gamry 1000 Interface potentiostat utilizing a three electrodes cell.
A spiral platinum wire was used as a counter electrode, the reference electrode used was $\mathrm{Ag} / \mathrm{AgCl}$ while the alloy's coupons prepared were used as working electrode in the tests.

The tests were conducted in $250 \mathrm{~mL}$ glass container with a glass top designed for this purpose.

The polarization curves were recorded for scanning the electrode potential from -0.5 to $1.5 \mathrm{~V}$ (vs. SCE) with $1 \mathrm{mV} / \mathrm{s}$ scanning rate.

\subsubsection{Dynamic corrosion}

For dynamic corrosion the samples were immersed in $250 \mathrm{~mL}$ DIW having different concentrations of $\mathrm{H}_{2} \mathrm{O}_{2}$ in beakers on magnetic stirrer.

The revolutions per minute were adjusted to provide linear velocities of 1,2 and $5 \mathrm{~m} / \mathrm{s}$. All the testes were repeated three times and average values of corrosion rate is reported.

The corrosion rate was determined via weight loss measurements using the following equation

$$
V_{a}=C \times \frac{W o-W}{\rho A t}
$$

where, $V_{a}$ is the corrosion rate or the annual speed, $\mathrm{mm} / \mathrm{y}, \mathrm{C}$ is the conversion factor, which is equal to $8.76 \times 10^{4}, \mathrm{~W}_{\mathrm{o}}$ is sample's weight (g) before test, $W$ is sample's weight (g) after test, $\rho$ is the density of the sample, which is equal $\left(2.7 \mathrm{~g} . \mathrm{cm}^{-3}\right), \mathrm{A}$ is working or exposed to environment area of the sample $\left(\mathrm{cm}^{2}\right)$ and $t$ is the testing time in hours.

\subsubsection{Surface roughness measurement}

The samples prepared were ultra-sonicated in DI water for $10 \mathrm{~min}$, degreased with acetone and dried with pressurized air.

The surface roughness was determined using DEKTAK 6M stylus profile which measure the roughness values in $\mathrm{X}-\mathrm{Y}$ dimensions.

The roughness measurements were repeated three times with a scan area of $3 * 3 \mathrm{~mm}^{2}$ and the average values were taken.

\section{Results and Discussion 3.1. Hardness measurement}

Figure 1 demonstrates the hardness measurements evaluation of the $\mathrm{Al}-\mathrm{Cu}-\mathrm{x} \mathrm{Sn}$ samples.

The results show that the hardness of the alloy with $1 \%$ tin $(\mathrm{Sn})$ has the highest value however after further increase of Sn alloy the hardness decreases.

This change in the hardness affects the corrosion rate of the alloy i.e. higher corrosion rates have been obtained for samples with lower hardness and vice versa as shown sections 3.3 and 3.4. 


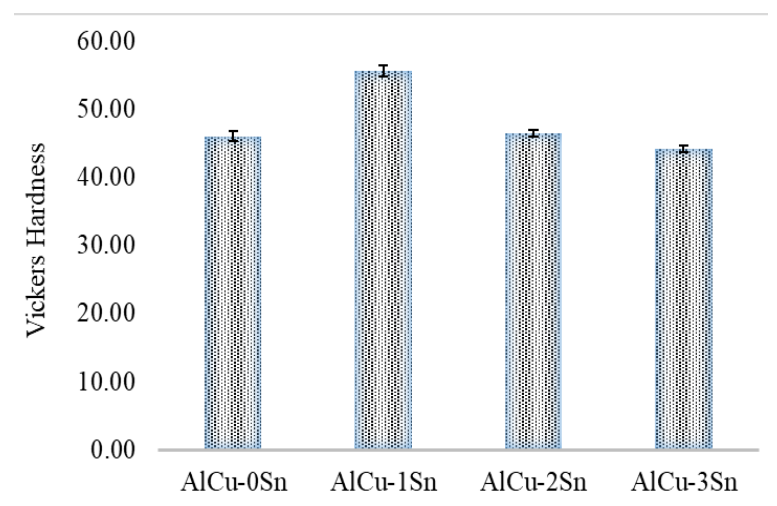

Figure 1: Vicker's Hardness of the alloys

\subsection{Contact angle measurement}

Figure 2 shows the wettability analyses of $\mathrm{AlCu}$ $\mathrm{xSn}$ alloy. It can be seen that the addition of $1 \% \mathrm{Sn}$ to the AlCu-xSn alloy decreases its wettability as compared to the baseline (AlCu-0Sn). However, upon further increase in $\mathrm{Sn}$ concentration in the alloy results in decrease in contact angle of DIW on the alloy's surface i.e. the wettability increases with increasing concentration of $\mathrm{Sn}$ in the alloy which is expected to affect its corrosion resistance.

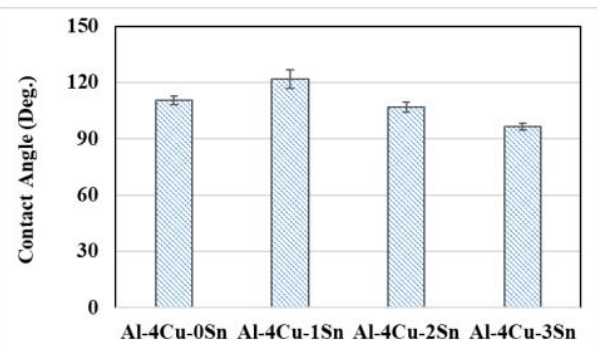

Figure 2. Contact angles (deg) of DIW on Al4CuxSn alloy's surface

\subsection{Potentiodynamic polarization}

Table 2. list the electrochemical parameters of $\mathrm{AlCu}-\mathrm{xSn}$ alloy in the presence of different concentration of $\mathrm{H}_{2} \mathrm{O}_{2}$. It can be seen that the alloy offers greater resistance to corrosion in DIW in the absence of $\mathrm{H}_{2} \mathrm{O}_{2}$.

The corrosion rate has been observed to increase with increasing concentration of $\mathrm{H}_{2} \mathrm{O}_{2}$ in the electrolyte. Moreover, as we increase the $\mathrm{Sn}$ concentration from 0 to 1 in the alloy the corrosion rate increases however with further increase in $\mathrm{Sn}$ concentration in the alloy the corrosion rate decreases. The decrease in corrosion rate can be attributed to the fact that the alloy becomes more wettable with increasing Sn concentration beyond 1 .

Table 2. Electrochemical parameters of AlCu-xSn alloy in the presence of different concentration of $\mathrm{H}_{2} \mathrm{O}_{2}$

\begin{tabular}{|c|c|c|c|c|c|}
\hline Solution & Tafel variables & AlCu-0Sn & $\mathrm{AlCu}-1 \mathrm{Sn}$ & $\mathrm{AlCu}-2 \mathrm{Sn}$ & AlCu-3Sn \\
\hline \multirow[t]{3}{*}{ DIW } & $\mathrm{I}_{\text {corr }}(\mathrm{u} A)^{*}+10^{-6}$ & 15.4 & 44 & 19.7 & 12.1 \\
\hline & $E_{\text {corr }}(\mathrm{mV})$ & 291 & 379 & 406 & -420 \\
\hline & CR (mm/year) & 0.25 & 0.68 & 0.3 & 0.19 \\
\hline \multirow[t]{3}{*}{$0.1 \% w t . \mathrm{H}_{2} \mathrm{O}_{2}$} & I corr $(\mathrm{u} A)^{*} 10^{-6}$ & 42.5 & 113 & 36.1 & 29.1 \\
\hline & $\mathrm{E}_{\text {corr }}(\mathrm{mV})$ & 39.9 & 111 & -113 & -152 \\
\hline & CR (mm/year) & 0.66 & 1.75 & 0.56 & 0.45 \\
\hline \multirow[t]{3}{*}{$0.2 \%$ wt. $\mathrm{H}_{2} \mathrm{O}_{2}$} & I corr $(\mathrm{u} A)^{*} 10^{-6}$ & 59.3 & 73.5 & 58.2 & 51.8 \\
\hline & $E_{\text {corr }}(\mathrm{mV})$ & 8.75 & 101 & -48.8 & -66.9 \\
\hline & CR (mm/year) & 0.96 & 1.19 & 0.903 & 0.802 \\
\hline \multirow[t]{3}{*}{$0.5 \%$ wt. $\mathrm{H}_{2} \mathrm{O}_{2}$} & $\operatorname{Icorr}(\mathrm{u} A)^{*} 10^{-6}$ & 68.7 & 64.9 & 93.9 & 54.7 \\
\hline & $E_{\text {corr }}(\mathrm{mV})$ & 86.5 & 120 & 31.1 & 151 \\
\hline & CR (mm/year) & 1.12 & 1.05 & 1.47 & 0.89 \\
\hline
\end{tabular}

\subsection{Dynamic corrosion}

The dynamic corrosion rates (mm/yr) of the alloy $\mathrm{AlCu}-\mathrm{xSn}$ as a function of Velocity $(\mathrm{m} / \mathrm{s})$ and $\mathrm{H}_{2} \mathrm{O}_{2}$ concentration in DIW is shown in Figure $3 a, b$ and $c$. The corrosion rate observed over a period of four hours for $\mathrm{AlCu}-0 \mathrm{Sn}$ is $0 \mathrm{~mm} / \mathrm{yr}$ in DIW at neutral $\mathrm{pH}$ which can be attributed to ability of aluminum forming a protective oxide layer on its surface.

The results obtained clearly show that the corrosion rate of the alloy rate is significantly high for $\mathrm{AlCu}-1 \mathrm{Sn}$ as compared to $\mathrm{AlCu}-0 \mathrm{Sn}$. However, when Sn concentration in the alloy increases more than 1 , a nearly linear decrease in corrosion rate has 
been observed. The observed dynamic corrosion rate is well in agreement with the corrosion rate obtained via Tafel fit for potentiodynamic polarization. Increasing velocity means increasing wall shear stress which in turn increases the corrosion rate i.e. the corrosion rates observed at $5 \mathrm{~m} / \mathrm{s}$ velocity are higher than at $2 \mathrm{~m} / \mathrm{s}$ velocity which in turn is higher than corrosion rates at a velocity of $1 \mathrm{~m} / \mathrm{s}$.

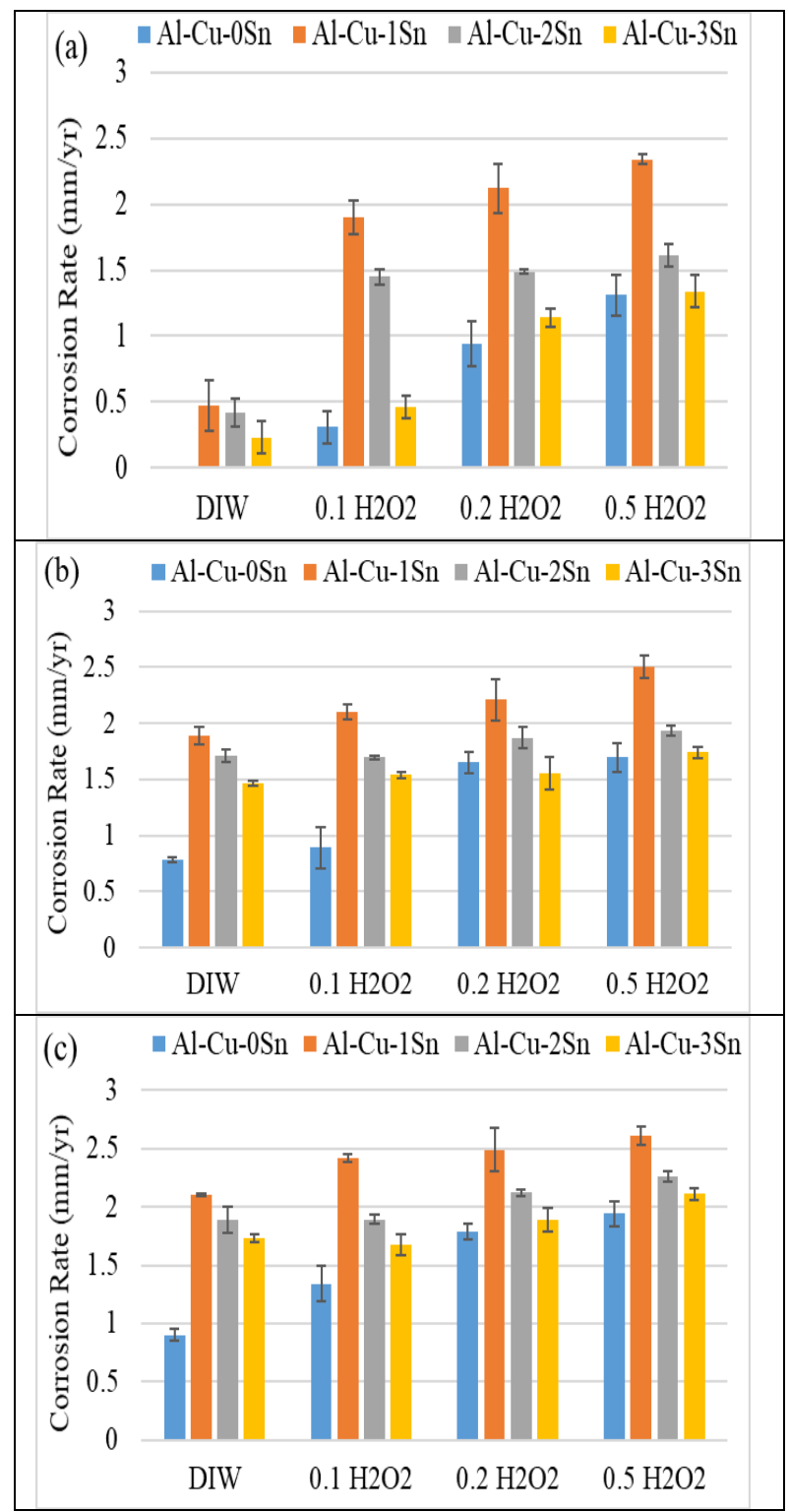

Figure 3. Corrosion rate as a function of $\mathrm{H} 2 \mathrm{O} 2$ concentration in the environment and Sn in $\mathrm{AlCu}-\mathrm{xSn}$ at (a) $1 \mathrm{~m} / \mathrm{s}$, (b) $2 \mathrm{~m} / \mathrm{s}$ and (c) $5 \mathrm{~m} / \mathrm{s}$ velocity.

\subsection{Surface roughness measurement}

Surface roughness of the alloy $\mathrm{AlCu}-\mathrm{xSn}$, after dynamic corrosion tests, as a function of Velocity $(\mathrm{m} / \mathrm{s})$ and $\mathrm{H}_{2} \mathrm{O}_{2}$ concentration in DIW is reported in Figure $\mathrm{a}, \mathrm{b}$ and $\mathrm{c}$. The alloy $\mathrm{AlCu}-1 \mathrm{Sn}$ has been found have highest corrosion rate for every concentration of $\mathrm{H}_{2} \mathrm{O}_{2}$ in DIW among the alloys tested.
Upon further addition of Sn (i.e. AlCu-2Sn AlCu-3Sn) the surface roughness decreases. The alloy corrodes faster as the velocity and/or concentration of $\mathrm{H}_{2} \mathrm{O}_{2}$ increases and results in higher surface roughness as shown in Figure $4 a$, b and c.

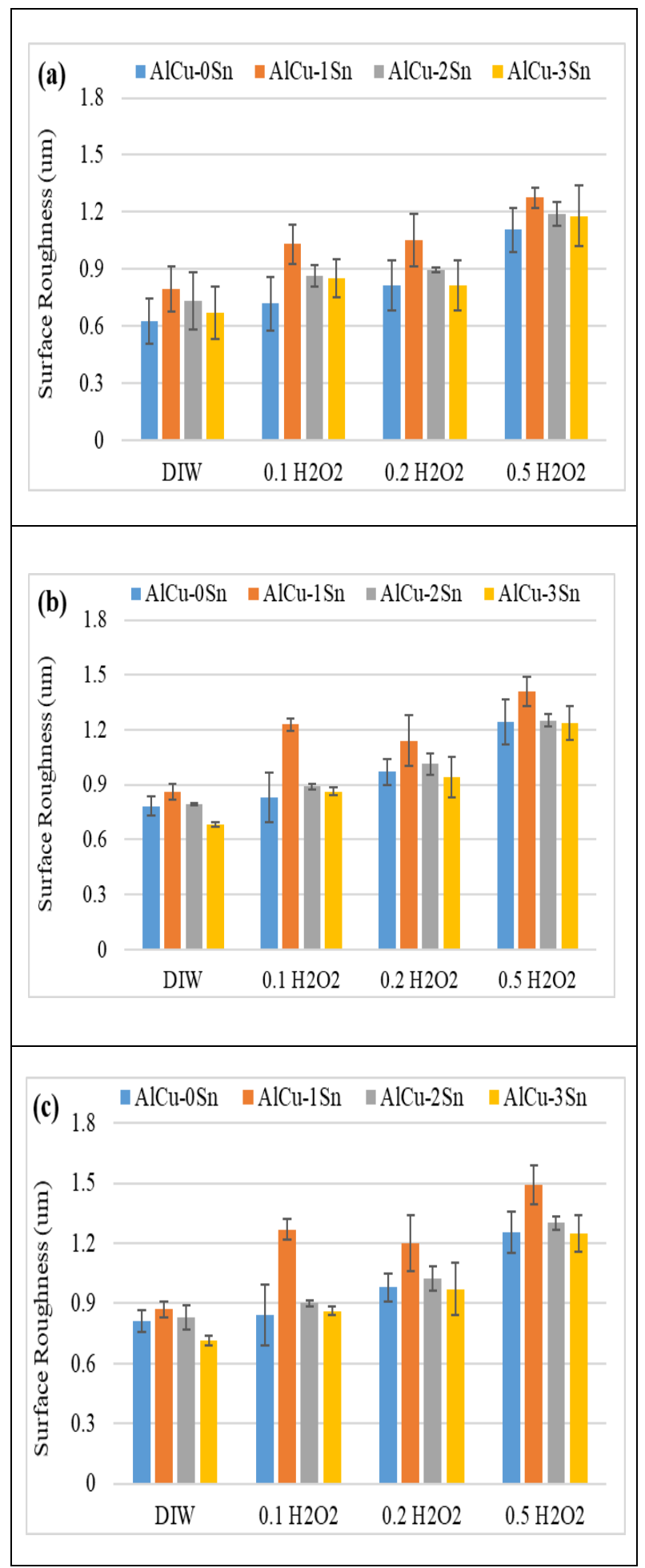

Figure 4. Surface roughness after dynamic corrosion as a function of $\mathrm{H} 2 \mathrm{O} 2$ concentration in the environment and Sn in AlCu-xSn at (a) $1 \mathrm{~m} / \mathrm{s}$, (b) $2 \mathrm{~m} / \mathrm{s}$ and (c) $5 \mathrm{~m} / \mathrm{s}$ velocity. 


\section{Conclusion}

Understanding corrosion behavior of has attracted the attention of many researchers because of their excellent properties and applications in several industries. In this study the corrosion behavior of $\mathrm{AlCu}-\mathrm{xSn}$ alloys as a function of $\mathrm{Sn}$ concentration in the alloy and $\mathrm{H}_{2} \mathrm{O}_{2}$ concentration in DIW under dynamic conditions. The alloys had the same surface roughness before dynamic corrosion experiments. However, after the experiments a significant difference in the surface roughness has been observed. The corrosion rates obtained for $1 \% \mathrm{Sn}$ in the alloy as compared to $\mathrm{Sn}$ free $\mathrm{AlCu}-\mathrm{xSn}$. However, from $1 \%$ to $3 \% \mathrm{Sn}$ in the alloy an almost linear decrease in corrosion rates have been observed. A similar trend has been seen in surface roughness of the alloys after dynamic corrosion experiments. This decreasing trend in the corrosion rates and surface roughness can be attributed to the wettability and hardness of the alloys.

\section{Acknowledgements (not mandatory)}

The authors would like to be obliged to Tikrit University for providing laboratory facilities and financial support.

\section{References}

[1] Aballe, A., Bethencourt, M., Botana, F. J., Cano, M. J., \& Marcos, M. 2001. Localized alkaline corrosion of alloy AA5083 in neutral $3.5 \% \mathrm{NaCl}$ solution. Corrosion science, 43(9), 1657-1674.

[2] Cheng, Y. L., Zhang, Z., Cao, F. H., Li, J. F., Zhang, J. Q., Wang, J. M., \& Cao, C. N. 2004. A study of the corrosion of aluminum alloy 2024-T3 under thin electrolyte layers. Corrosion Science, 46(7), 16491667.

[3] Hintze, P. E., \& Calle, L. M. 2006. Electrochemical properties and corrosion protection of organosilane self-assembled monolayers on aluminum 2024-T3. Electrochimica Acta, 51(8-9), 1761-1766.

[4] Khireche, S., Boughrara, D., Kadri, A., Hamadou, L., \& Benbrahim, N. 2014. Corrosion mechanism of $\mathrm{Al}, \mathrm{Al}-\mathrm{Zn}$ and $\mathrm{Al}-\mathrm{Zn}-\mathrm{Sn}$ alloys in $3 \mathrm{wt} . \% \mathrm{NaCl}$ solution. Corrosion Science, 87, 504-516.

[5] Gudić, S., Smoljko, I., \& Kliškić, M. 2010. The effect of small addition of tin and indium on the corrosion behavior of aluminium in chloride solution. Journal of alloys and compounds, 505(1), 54-63.

[6] Bessone, J. B., Salinas, D. R., Mayer, C. E., Ebert, M., \& Lorenz, W. J. 1992. An EIS study of aluminium barrier-type oxide films formed in different media. Electrochimica Acta, 37(12), 2283-2290.

[7] Adebayo, I. O., Bodude, M. A., \& Onovo, H. O. 2018. Study on Corrosion Inhibition Efficiency of Solanum Erianthum Extract on 6063 Aluminium Alloy in Different Sea Water.

[8] Rosliza, R. 2012. Improvement of corrosion resistance of aluminium alloy by natural products. Corrosion Resistance, 377-395.

[9] Szklarska-Smialowska, Z. 1992. Insight into the pitting corrosion behavior of aluminum alloys. Corrosion science, 33(8), 1193-1202.

[10] El Shayeb, H. A., El Wahab, F. A., \& El Abedin, S. Z. 1999. Electrochemical behaviour of $\mathrm{Al}, \mathrm{Al}-\mathrm{Sn}$, $\mathrm{Al}-\mathrm{Zn}$ and $\mathrm{Al}-\mathrm{Zn}-\mathrm{Sn}$ alloys in chloride solutions containing indium ions. Journal of applied electrochemistry, 29(4), 473-480.

[11] El Shayeb, H. A., El Wahab, F. A., \& El Abedin, S. Z. 1999. Electrochemical behaviour of $\mathrm{Al}, \mathrm{Al}-\mathrm{Sn}$, $\mathrm{Al}-\mathrm{Zn}$ and $\mathrm{Al}-\mathrm{Zn}-\mathrm{Sn}$ alloys in chloride solutions containing indium ions. Journal of applied electrochemistry, 29(4), 473-480.

[12] Munoz, A. G., \& Bessone, J. B. 1999. Pitting of aluminium in non-aqueous chloride media. Corrosion science, 41(7), 1447-1463.

[13] Flamini, D. O., Saidman, S. B., \& Bessone, J. B. 2006. Aluminium activation produced by gallium. Corrosion Science, 48(6), 1413-1425.

[14] Bessone, J. B., Flamini, D. O., \& Saidman, S. B. 2005. Comprehensive model for the activation mechanism of $\mathrm{Al}-\mathrm{Zn}$ alloys produced by indium. Corrosion science, 47(1), 95-105.

[15] Almansour, A., Azizi, M., Jesri, A. M., \& Entakly, S. 2015. Effect of Surface Roughness on Corrosion behavior of Aluminum Alloy 6061 in Salt Solution (3.5\% NaCl). Int. J. Acad. Sci. Res, 3, 37 45.

[16] Alvarez, R. B., Martin, H. J., Horstemeyer, M. F., Chandler, M. Q., Williams, N., Wang, P. T., \& Ruiz, A. 2010. Corrosion relationships as a function of time and surface roughness on a structural AE44 magnesium alloy. Corrosion Science, 52(5), 1635-1648.

[17] Flamini, D. O., \& Saidman, S. B. 2012. Electrochemical behaviour of Al-Zn-Ga and AlIn-Ga alloys in chloride media. Materials Chemistry and Physics, 136(1), 103-111. 